Voix et Images

\title{
Gaston Miron : les paradoxes de l'écriture poétique, les dénégations, la lucidité
}

\section{Jean Fisette}

Volume 16, numéro 1 (46), automne 1990

Les correspondants littéraires d'Alfred DesRochers

URI : https://id.erudit.org/iderudit/200881ar

DOI : https://doi.org/10.7202/200881ar

Aller au sommaire du numéro

Éditeur(s)

Université du Québec à Montréal

ISSN

0318-9201 (imprimé)

1705-933X (numérique)

Découvrir la revue

Citer cet article

Fisette, J. (1990). Gaston Miron : les paradoxes de l'écriture poétique, les dénégations, la lucidité. Voix et Images, 16(1), 146-149.

https://doi.org/10.7202/200881ar d'utilisation que vous pouvez consulter en ligne.

https://apropos.erudit.org/fr/usagers/politique-dutilisation/ 


\section{Gaston Miron: les paradoxes de l'écriture poétique, les dénégations, la lucidité}

par Jean Fisette, Université du Québec à Montréal

Une correspondance à la limite du journal intime...

Th n'en crois rien et pourtant c'est bien moi. $\dot{A}$ moi-même comme à toi il me semble que je reviens toujours d'un très long voyage je ne sais où, où ça ténèbre, où ça pagaie, tour à tour naufragé, sain et sauf, de nouveau emporté, encore revenu. 1

Gaston Miron est un homme de camaraderie, d'amitiés, on le sait: à ce point d'ailleurs qu'il symbolisa, à lui seul, durant plusieurs années, ce projet à la fois poétique et politique qui anima toute une génération. Ses diverses activités dans le monde littéraire ont toujours porté cette empreinte du travail collectif, que ce soit le travail d'éditeur, d'animateur ou celui de l'écriture. Nous devons aujourd'hui à l'une de ces relations de camaraderie un document qui s'avère extrêmement intéressant à plus d'un titre, soit la correspondance qu'il échangea durant plus d'une dizaine d'années (entre 1954 et 1965) avec Claude Haeffely. Pierre Filion présente cette publication sous le titre d'À bout portant.

La publication d'une correspondance représente une démarche toujours risquée en ce qu'il y a un détournement du destinataire unique vers un public élargi; les catégories de la vie privée et de l'échange public se croisent, l'intime devient valeur collective. Cette situation ambiguë est encore renforcée ici du fait que nous n'avons accès qu'aux seules lettres de Miron ${ }^{2}$, ce qui déplace le genre à la limite du journal intime. C'est donc dire que cet ouvrage devient, en quelque sorte, inclassable. Les découvertes que l'on y fait sont peutêtre liées à cet aspect bigarré: Miron est un homme prompt, vivace, émotif, emporté et le rythme de la phrase, écrite spontanément, reproduit cette "respiration" de la communication directe. La lecture de cette correspondance nous entraîne au long d'une tranche de vie, suivant ces diverses modalités affectives, où les événements privés et collectifs se superposent constamment.

Jacques Brault nous avait déjà parlé de Miron le magnifique ${ }^{3}$; celui que nous retrouvons ici, c'est un homme aux multiples 
dimensions, successivement emporté par la passion dévorante et replié sur la douleur de l'échec amoureux. Ce que nous donne cette édition, c'est le creuset peut-être moins de la poésie que des conditions dans lesquelles l'événement littéraire qu'a été Miron a évolué durant ces années centrales de la création de l'Hexagone et de l'écriture de l'Homme rapaillé. C'est un épisode de notre histoire littéraire qui est ici mis en scène du point de vue de l'un de ses plus illustres représentants.

\section{La dénégation}

L'effort inoui, inimaginable, que nous. avons dî fournir, pour nous mettre au monde. Cela nous a tout pompé, jusqu'à notre ombre. Un jour, comme c'est le cas pour moi, nous en perdons la mémoire. La mémoire martyre. Je vis depuis deux ans sous le signe de l'Amnésie.' Je dois produire une énergie atomique pour parvenir au simple usage de la parole. Le mal, c'est la confusion. La confusion, c'est un ter. rain vague sous nos pieds. Nous devons chercher nos mots à quatre pattes dans le trou-vide. Même pour nommer (même pas pour dire) les choses les plus élémentaires, les besoins les plus vitaux de notre nature, les objets qui tombent sous nos yeux. Que m'est-il arrivé Que nous arrive$t$-il? (p. 63)

L'image la plus répandue de Gaston Miron est celle du poète aux prises avec la difficulté d'écrire et nul doute qu'un texte tel que "Notes sur le non-poème et le poème" ait contribué à répandre cette impression que Miron lui-même ne cesse de confirmer, rejetant son statut de poète. On a pu voir là une coquetterie. L'apport qui me paraît le plus important de cette publication réside précisément ici: ce sentiment d'impuissance, de lutte impérative y trouve sa contextualisation et prend donc de nouvelles dimensions. Certes, on y retrouve le Miron bien connu qui rejette sa qualité de littéraire, ses capacités à créer de la poésie, à exprimer l'âme du peuple; puis se succèdent les dénégations: il n'aurait pas lu les grands auteurs alors qu'ailleurs il affirme lire la poésie à la tonne, puis il raconte sa découverte ébahie de Césaire; ses lectures, ses préoccupations intellectuelles l'ont conduit d'abord aux grandes œuvres critiques de la pensée sociale et philosophique: Adorno, Hegel, Lévi-Strauss, Lukács, etc.; l'activité de la poésie n'aurait été, chez lui, qu'un 
accompagnement nécessaire à la vie amoureuse, une échappée éphémère aux nécessités de l'action sociale.

Pourtant, ces lettres ne traitent que de production de texte, des conditions difficiles d'accès à l'écriture de la poésie. En même temps qu'il dénie son accès à la poésie (LA POÉSIE CHEZ MOI EST UNE IMPOSTURE, écrit-il, en majuscules), Miron glisse dans les enveloppes des poèmes (réédités dans cet ouvrage).

Au fil' du texte, on se rend compte que l'activité de l'écriture ne peut constituer un en soi, la poésie, une valeur pour elle-même. Ce qui manque, c'est une institution littéraire qui conférerait une valeur au simple poème. On comprend alors que l'activité de Miron soit globale; l'animation d'un milieu de créateurs, la présence lors de foires, l'organisation du colloque de Montmorency en 1957 intitulé "La poésie et nous" 4 , la participation au périodique franco-québécois (eh oui! déjà à l'époque) le Périscope dirigé par son correspondant, Claude Haeffely, puis la représentation des jeunes poètes dans les médias.

Et, lorsque la lueur d'espoir se perd dans l'obscurité, Miron se retourne vers ses arrières, vers ses racines: attirance pour le culte religieux de l'enfance, nostalgie des ancêtres (Je reviendrai aux travaux du bois, comme mon père, mon grand-père, qui étaient tous des hommes de bois. Cette nostalgie me hante depuis des années [p. 73]) Pourtant, il revient toujours à l'écriture.

La thématique de l'enracinement dans le pays devient elle-même le lieu d'un paradoxe: l'écriture implique un arrachement du pays parce qu'elle suppose l'accès à l'institution alors que le "pays" n'est pas reconnu par l'institution; et, simultanément, seul l'attachement au pays peut conférer un sens à l'écriture de la poésie.

Et, dans cette foulée, s'accumulent les paradoxes qui fondent la spécificité de l'imaginaire chez Miron: l'appartenance nécessaire à la culture américaine (Tant que les Canadiens d'expression française ne s'américaniseront pas, ils ne produiront rien de rien, ils seront les bâtards d'une culture qu'ils ne peuvent assumer... [p. 72-73]), mais la fascination pour la culture française (Bonjour à la France, et au soleil qui ne peut être que français! [p. 44]).

Miron n'a de cesse de se référer à l'urgence de l'action sociale: en 1957, il se porte candidat dans le comté d'Outremont sous la bannière du Parti social-démocrate, mais, en 1960, alors que toute la situation politique du Québec est virtuellement en train de se renverser, il est en Europe et l'on ne trouve aucune allusion à cet événement majeur. La conscience politique s'aiguise chez Miron en 1956, à l'occasion des événements du canal de Suez et de ceux de Hongrie, mais alors la rencontre des événements et des discours est incohérente; c'est le pouvoir même de la parole qui est remis en 
cause, dans cette cruelle rencontre du discours de gauche représentant le seul espoir et du suicide de Maïakovski: nous sommes devant une situation extrême et une extrême impuissance. [...] Le bon mur des paroles. Nous faisons tous semblant d'y croire. Mais au fond de son cœur tout homme n'en est pas sûr, parce que tout homme jauge présentement sa faiblesse (p. 54).

Alors, où la parole prendra-t-elle appui ? Dans la vie personnelle, dans l'interaction sociale? Me semble, ajoute-t-il, qu'écrire devient absurde. Et pourtant, le langage est peut-être le seul et dernier honneur. (p. 55)

Je crois que la poésie essentielle, chez Miron, réside dans cette cascade de paradoxes et c'est ce que vient illustrer cette édition. Après cette lecture, la poésie de "La vie agonique», celle de "La marche à l'amour", loin de représenter le sentiment d'impuissance, témoigne à la fois de la nécessité et de la précarité de la parole, de l'institution qui la rend possible.

\section{“La poésie dégagée, engagée "}

J'essaie bien d'affronter le plus de largeur du réel. Oui, je continuerai le plus possible, jusqu'à la corde usée de ma voix, de lutter pour une culture qui rend libre. (p. 55)

On a pu penser, à une certaine époque, que Miron était un poète romantique. Cette correspondance nous force à reconnaitre que le poète est pleinement moderne, intégrant avec une intériorité marquée par l'émotion généreuse qu'on lui connaît le choc des événements sociaux et politiques, assumant avec courage et lucidité le paradoxe inhérent à tout langage. On ne peut qu'être reconnaissant à Claude Haeffely et à Pierre Filion d'avoir révélé cette correspondance. La voix brisée, hésitante, hachurée de Miron témoigne d'un aspect fondamental de notre culture occidentale.

1 Gaston Miron, À bout portant. Correspondance de Gaston Miron à Claude Haeffely. 1954-1965, édition préparée par Pierre Filion, Montréal, Leméac, 1989, 174 p. (p. 47).

2 Les lettres de Claude Haeffely, au dire de l'éditeur, n'auraient pas été retrouvées dans les dossiers de Miron. Hacffely a cependant rédigé de courts fragments relatant les événements nécessaires pour comprendre la séquence des lettres de Miron.

3 Jacques Brault, Miron le magnifique, Montréal, P.U.M., 1966 ("Conférence J.-A. de Sève»).

4 La Poésie et nous, Montréal, l'Hexagone, 1958, 93 p. 